\title{
On the contribution of Aitken mode particles to cloud droplet populations at continental background areas - a parametric sensitivity study
}

\author{
T. Anttila and V.-M. Kerminen \\ Finnish Meteorological Institute, Research and Development, P.O. Box 503, 00101 Finland \\ Received: 23 March 2007 - Published in Atmos. Chem. Phys. Discuss.: 8 May 2007 \\ Revised: 29 August 2007 - Accepted: 10 September 2007 - Published: 12 September 2007
}

\begin{abstract}
Aitken mode particles are potentially an important source of cloud droplets in continental background areas. In order to find out which physico-chemical properties of Aitken mode particles are most important regarding their cloud-nucleating ability, we calculated the number of cloud droplets formed on Aitken mode particles, $C D_{2}$, with an adiabatic air parcel model. The model output was analyzed using a global sensitivity analysis method that quantifies and ranks the relative importance of the considered input parameters to the total variance of $C D_{2}$. The results show that unless the particle surface tension or the mass accommodation coefficient of water is strongly reduced due to the presence of surface-active organics, the parameters describing the size distribution are generally more important than the particle chemical composition. In the absence of such compounds, the chemical composition may have roughly an equal importance with the size distribution only at low updraft velocities characterized by maximum supersaturations below $0.1 \%$. Furthermore, the largest source of variability is generally the particle number concentration, followed by the particle size. The performed sensitivity analysis revealed that the variability of the particle chemical composition may dominate the total variation of $C D_{2}$ if: 1 ) the value of $\alpha$ varies at least one order of magnitude more than what is expected for pure water surfaces $\left(10^{-2}-1\right)$, or 2$)$ the particle surface tension varies more than roughly $30 \%$ under conditions close to reaching saturation.
\end{abstract}

\section{Introduction}

One of the main sources of uncertainty in current predictions concerning the climate change arises from large difficulties in predicting reliably the microphysical structure of

Correspondence to: T. Anttila

(tatu.anttila@fmi.fi) clouds, in particular the number concentration and size of cloud droplets (Menon, 2004; Chen and Penner, 2005). Since atmospheric aerosol particles act as nuclei onto which cloud droplets are formed, these uncertainties are closely tied to our incomplete knowledge regarding the sources and physicochemical properties of atmospheric aerosols (Lohmann and Feichter, 2005; McFiggans et al., 2006).

Aerosol particles need to contain sufficient amounts of water-soluble material in order to form cloud droplets in the atmosphere. The minimum particle diameter required for acting as cloud condensation nuclei in the atmosphere is determined by complex interactions between cloud dynamics and aerosol particle population, but varies typically between 50 and $100 \mathrm{~nm}$ in the lower troposphere (Seinfeld and Pandis, 1998). This size range is also characteristic for the Aitken mode particles, the physico-chemical properties of which depend strongly on the aerosol origin. Given that the Aitken mode particles often make dominant contribution to the total particle number concentration in the size range $>50 \mathrm{~nm}$ in continental areas (Tunved et al., 2003), it is therefore highly desirable to understand the connection between the Aitken mode particles and the cloud microphysics in these areas.

The climatic effects of Aitken mode particles, formed either in the atmosphere or emitted from surface-based sources, can be quantified with regional and/or or global models (e.g. Adams and Seinfeld, 2002; Spracklen et al., 2005; Stier et al., 2005). Due to the various spatial scales involved, microphysical processes have to be described in a computationally efficient way while simultaneously maintaining a sufficient level of accuracy in such models. To make an optimal compromise between computational costs and realism, the key parameters governing the climatic effects of Aitken mode particles should be identified, and most of the effort should be devoted to capturing accurately the time development of these parameters. To this end, our aim is to give an answer to the following question: "which physico-chemical properties of Aitken mode particles are

Published by Copernicus Publications on behalf of the European Geosciences Union. 
most important regarding their contribution to cloud droplet number concentrations?". Providing an answer to this question would help us to prioritize the research needs also in the field of experimental aerosol research.

We approach the problem by investigating the sensitivity of the number concentration of cloud droplets formed on Aitken mode particles to the physico-chemical properties of these particles. The approach relies on performing model calculations with an adiabatic air parcel model and analyzing the model output with the probabilistic collocation method (PCM), a tool for sensitivity analysis (Tatang et al., 1997). Here we would like to note that studies adopting somewhat similar approaches have been conducted previously (e.g. Feingold, 2003; Rissman et al., 2004; Ervens et al., 2005 and references therein; Chuang, 2006). However, the approach of the current paper is novel in two ways. First, the focus is solely on the impact of Aitken mode particles to cloud microphysics and not that of the whole particle population. This choice is largely motivated by the current research interest in new particle formation and its climatic implications (Kurten et al., 2003; Kulmala et al., 2004; Kerminen et al., 2005; Spracklen et al., 2006). Second, we employ a socalled "global" method for sensitivity analysis, in contrast to "local" methods used in the above-cited studies. There are dedicated papers discussing the differences between these two approaches (e.g. Saltelli, 1999a, b), and thus it suffices to point out two major advantages of the "global" method over the "local" one: 1) the model sensitivity to uncertainty or variability in the input parameter values is quantified over the whole parameter space or over a parameter space region, and 2) the net effects of simultaneously varying input parameters are accounted for. Furthermore, we focus on conditions typical to continental background air masses. New particle formation takes place regularly under such conditions and the newly-formed particles, after their growth to Aitken mode sizes which occurs typically over timescales of $5-50 \mathrm{~h}$, are able to contribute to the cloud droplet concentrations (Komppula et al., 2005 and references therein; Kerminen et al., 2005). Consequently, the results of the study are directly relevant to understanding the climatic effects of new particle formation taking place over large parts of the globe.

\section{Approach}

We approach the problem by a combination of model simulations performed with an adiabatic air parcel model (AAPM, Anttila and Kerminen, 2002) and sensitivity analysis using the probabilistic collocation method (PCM, Tatang et al., 1997). The AAPM is used to predict the number concentration of cloud droplets formed on Aitken mode particles, $C D_{2}$, during an air updraft. Here input parameters describing the physico-chemical properties of Aitken mode particles are treated as independent random variables.
The PCM is a technique that quantifies the sensitivity of the model output to uncertainty or variability in the input parameters values. In order to save computing time compared with a full Monte Carlo analysis, the model output is approximated by polynomials termed as polynomial chaos expansions (PCEs), the terms of which are functions of the considered input parameters. Free coefficients in the PCEs are determined so that the PCEs give an optimal approximation for the true model output in the high probability regions of the parameter space. The required statistical properties of the model output can be readily extracted from the PCEs, allowing for a global characterization of the model sensitivity.

\subsection{Air parcel model}

The applied AAPM has been described in detail by Anttila and Kerminen (2002). Briefly, the model solves equations governing the time development of a population of aerosol particles and cloud droplets in an air parcel that rises adiabatically with a constant velocity. The particle size distribution is assumed to consist of an Aitken and accumulation mode, and particles are divided into two separate grids with 100 size bins each according to their mode. This allows for a straightforward determination of $C D_{2}$ at the cloud top. The thermodynamic driving force behind the growth or evaporation of a particle/droplet during an air updraft is the difference $\left(S-S_{\text {eq }}\right)$, where $S$ is the saturation ratio of water vapour and $S_{\text {eq }}$ is the equilibrium saturation ratio of water over the particle/droplet surface. The former quantity, $S$, is determined by a balance between the cooling of the air parcel and transfer of water vapour onto particles and droplets. The quantity $S_{\text {eq }}$, in turn, is calculated using the Köhler equation (Seinfeld and Pandis, 1998) and is a function of the particle/droplet size and its chemical composition. To be more specific, $S_{\text {eq }}$ depends on the particle/droplet surface tension, solution nonidealities and the number of molecules dissolved into the aqueous phase. For a particle with a given mass, the last of these quantities depends on the density and molecular weight of the solute molecules as well as on their tendency to dissociate in the aqueous phase.

Following previous modeling studies utilizing an adiabatic air parcel model, we quantify the sensitivity of the cloud droplet formation to the particle chemical composition by assuming that particles contain only a single solute (Feingold, 2003; Ervens et al., 2005). It is also assumed that the solute dissolves entirely into the aqueous phase. Slightly-soluble compounds, which dissolve only partially, are not considered because the effects of limited solubility are clearly exceeded by those of varying soluble mass fraction (Ervens et al., 2005; McFiggans et al., 2006). Furthermore, our model does not account for the surface/bulk partitioning of the solute which may influence the cloud-nucleating ability of particles (Sorjamaa et al., 2004; Kokkola et al., 2006; Sorjamaa and Laaksonen, 2006). This is because the particle/droplet surface tension is assumed to be constant in the 
model (Sect. 2.3), whereas the surfactant partitioning can be calculated only if the surface tension is allowed to depend on the solute concentration (Sorjamaa and Laaksonen, 2006).

\subsection{Application of PCM}

Comprehensive descriptions of PCM can be found in the literature (Tatang et al., 1997; Isukapalli, 1999; Lucas and Prinn, 2005), and therefore only a brief outline is given here.

In our application, the goal is to find a PCE that approximates $\ln \left(C D_{2}\right)$. The natural logarithm of $C D_{2}$ is approximated rather than $C D_{2}$ in order to avoid unphysical predictions that might arise when approximating $C D_{2}$ with polynomials. We treat all varied input variables or, if the value range is more than one order of magnitude, their logarithms as uniformly distributed random variables $\phi_{i}, i=1, \ldots, N$, where $N$ is the number of the varied input parameters. Furthermore, in order to simplify calculations, we re-scale the variables $\phi_{i}$ so that they are all distributed uniformly in the range $[-1$, $1]$ and consequently a new set of random variables $\psi_{i}$ is obtained:

$\psi_{i}=\frac{2 \varphi_{i}-\left(b_{i}+a_{i}\right)}{\left(b_{i}-a_{i}\right)}$,

where $\left[a_{i}, b_{i}\right]$ is the value range of $\phi_{i}$.

The PCEs generated here consist of a sum of orthogonal polynomials which are functions of $\psi_{i}$ and depend on the probability distributions of $\psi_{i}$. For random variables distributed uniformly in the range $[-1,1]$, the corresponding orthogonal polynomials are Legendre polynomials (Table 1). The accuracy of a polynomial approximation increases generally with increasing order of the polynomials, but consequently also the computing time increases. Hence, in order to keep the computational burden reasonable while maximizing the accuracy, PCEs used here are of fourth order with respect to homogeneous terms and of third order with respect to cross terms. Ternary or higher order products of $\psi_{i}$ are not considered. Consequently, the generated PCEs for $\ln \left(C D_{2}\right)$ have the following form:

$$
\begin{aligned}
\Gamma=\alpha_{0} & +\sum_{j=1}^{4} \sum_{k=1}^{N} \alpha_{j, k} P_{j}\left(\psi_{k}\right) \\
& +\sum_{k=1}^{N-1} \sum_{j=k+1}^{N} \beta_{j, k} P_{1}\left(\psi_{k}\right) P_{1}\left(\psi_{j}\right) \\
& +\sum_{k=1}^{N} \sum_{j=1, j \neq k}^{N} \gamma_{j, k} P_{1}\left(\psi_{k}\right) P_{2}\left(\psi_{j}\right) .
\end{aligned}
$$

Here $\alpha_{0}$ and $\alpha_{j, k}$ are coefficients related to the homogeneous part of the PCE, $P_{j}$ is $j$-th order Legendre polynomial (see Table 1), and $\beta_{j, k}$ and $\gamma_{j, k}$ are coefficients related to the heterogeneous part of the PCE. It should be noted that PCEs can be also used to parameterize model output (e.g. Calbó et al., 1998; Mayer et al., 2000), but here we use PCM solely as a tool for sensitivity analysis.
Table 1. Legendre polynomials $\left(P_{n}\right)$ contained by Eq. (2) and the integrals $E\left(P_{n}\right)$ and $E\left(P_{n}^{2}\right)$ (Eq. 3).

\begin{tabular}{clcc}
\hline Order & $P_{n}(x)$ & $E\left(P_{n}\right)$ & $E\left(P_{n}^{2}\right)$ \\
\hline 0 & 1 & 1 & 1 \\
1 & $x$ & 0 & $1 / 3$ \\
2 & $1 / 2 \times\left(3 x^{2}-1\right)$ & 0 & $1 / 5$ \\
3 & $1 / 2 \times\left(5 x^{3}-3 x\right)$ & 0 & $1 / 7$ \\
4 & $1 / 8 \times\left(35 x^{4}-30 x^{2}+3\right)$ & 0 & $1 / 9$ \\
\hline
\end{tabular}

The coefficients $\alpha_{0}, \alpha_{j, k}, \beta_{j, k}$ and $\gamma_{j, k}$ are determined as follows. First $C D_{2}$ is calculated using the AAPM in certain points of the parameter space. In our case, these so-called collocation points are formed from the roots of fifth order Legendre polynomials (Tatang et al., 1997). In the standard formulation of PCM, the number of model runs used to determine coefficients in Eq. (2) is equal to the number of coefficients (Tatang et al., 1997). In order to increase the accuracy of the PCEs, we performed twice that many simulations (Isukapalli, 1999). By substituting the model-generated output to the left-hand side of Eq. (2) and the corresponding input parameter values to the right-hand size of Eq. (2), we obtain a set of linear equations for the coefficients $\alpha_{0}, \alpha_{j, k}$, $\beta_{j, k}$ and $\gamma_{j, k}$. The system is solved using the singular value decomposition technique which yields also an optimal agreement between the model and PCE in the collocation points in the least-squares sense (Press et al., 1992).

$\Gamma$ is a random variable which approximates the original model output, and therefore several useful statistical properties describing the model behavior can be extracted from Eq. (2) once the coefficients have been determined. The subsequent results are based on calculating the following integrals:

$E\left(P_{n}^{j}\right)=\frac{1}{2} \int_{-1}^{1} P_{n}^{j}(x) d x$,

where $E\left(P_{n}^{j}\right)$ is the expectation value of n-th order Legendre polynomial which is raised to the $\mathrm{j}$-th power. The values of the required integrals are shown in Table 1. By using the independency of the variables $\psi_{i}$ and the orthogonality of Legendre polynomials, the expected value, $E(\Gamma)$, and variance, $\operatorname{Var}(\Gamma)$, readily follow:

$$
\begin{aligned}
E(\Gamma)= & \alpha_{0}, \\
\operatorname{Var}(\Gamma)= & \sum_{j=1}^{N}\left(\frac{1}{3} \alpha_{1, j}^{2}+\frac{1}{5} \alpha_{2, j}^{2}+\frac{1}{7} \alpha_{3, j}^{2}+\frac{1}{9} \alpha_{4, j}^{2}\right) \\
& +\frac{1}{9} \sum_{k=1}^{N-1} \sum_{j=k+1}^{N} \beta_{j, k}^{2}+\frac{1}{15} \sum_{k=1}^{N} \sum_{j=1, j \neq k}^{N} \gamma_{j, k}^{2} .
\end{aligned}
$$


Table 2. Investigated parameters, their abbreviations and ranges over which their values were varied. All the parameters refer to Aitken mode particles and not to the whole particle population.

\begin{tabular}{|c|c|c|c|c|}
\hline Parameter & Abbreviation & "BASE" & "MACRO" & "FILM" \\
\hline Geometric standard deviation & $\sigma_{g}$ & $1.3-1.9$ & $1.3-1.9$ & $1.3-1.9$ \\
\hline Total particle concentration $\left(\mathrm{cm}^{-3}\right)$ & $C N$ & $10-10000$ & $10-10000$ & $10-10000$ \\
\hline Particle mean diameter $(\mathrm{nm})$ & $D_{m}$ & $50-100$ & $50-100$ & $50-100$ \\
\hline Average molecular weight $\left(\mathrm{g} \mathrm{mol}^{-1}\right)$ & $M W_{\text {avg }}$ & $60-250$ & $60-600$ & $60-250$ \\
\hline Water-soluble mass fraction & $\varepsilon$ & $0.25-1.0$ & $0.25-1.0$ & $0.25-1.0$ \\
\hline Particle dry density $\left(\mathrm{g} \mathrm{cm}^{-3}\right)$ & $\rho$ & $1.0-2.0$ & $1.0-2.0$ & $1.0-2.0$ \\
\hline "Effective" Van't Hoff factor & $v \Phi$ & $1-3$ & $1-5$ & $1-3$ \\
\hline Particle surface tension $\left(\mathrm{N} \mathrm{m}^{-1}\right)$ & $\sigma_{s}$ & $0.05-0.072$ & $0.02-0.072$ & $0.05-0.072$ \\
\hline Mass accommodation coefficient & $\alpha$ & $10^{-2}-1$ & $10^{-2}-1$ & $10^{-3}-1$ \\
\hline
\end{tabular}

As seen, the expression for $\operatorname{Var}(\Gamma)$ includes a summation over $N$, which provides a means to decompose the total variance into the contributions from each variable $\psi_{i}$ :

$$
\begin{aligned}
\operatorname{Var}\left(\psi_{i}\right)= & \frac{1}{3} \alpha_{1, i}^{2}+\frac{1}{5} \alpha_{2, i}^{2}+\frac{1}{7} \alpha_{3, i}^{2}+\frac{1}{9} \alpha_{4, i}^{2}+\frac{1}{9} \sum_{j=1, j \neq i}^{N} \frac{\beta_{j, i}^{2}}{2} \\
& +\frac{1}{15} \sum_{j=1, j \neq i}^{N}\left(\frac{\gamma_{j, i}^{2}}{2}+\frac{\gamma_{i, j}^{2}}{2}\right) .
\end{aligned}
$$

The factor $1 / 2$ appearing in the last two terms in the righthand side of Eq. (2) is due to the fact that $\psi_{i}$ and $\psi_{j}$ have the same probability distribution, which implies that the cross-terms contributions distribute evenly between these variables. Expression (5) is of central importance to the further considerations, since it provides a measure to the contribution of each varied model parameter $\phi_{i}$ to the total variance in the model output.

\subsection{Performed sensitivity studies}

Here the focus is on the properties of Aitken mode particles, not those of larger background particles. Therefore we assume that the background particles comprise a single mode with constant properties characteristic to continental remote areas. Thus, the background mode particles consist of ammonium bisulfate and have mode mean diameter of $200 \mathrm{~nm}$, total number concentration of $250 \mathrm{~cm}^{-3}$ and geometric standard deviation of 1.45 . The surface tension of background particles and droplets formed on them is assumed to be equal to that of pure water. In addition, the mass accommodation coefficient of water onto background particles and droplets formed on them is set equal to unity.

The updraft velocity of an air parcel, $V$, is a crucial model parameter which determines, together with the aerosol population, the number concentration of cloud droplets formed during an air ascent. In order to explore a range of supersaturations and to improve the accuracy of PCEs, the PCEs were generated separately for each applied value of $V$ which were
$0.2,0.4,0.6,0.8$ and $1.0 \mathrm{~m} / \mathrm{s}$. We also generated PCEs for lower updraft velocities, but the accuracy of the PCEs were notably worse compared to results obtained for $V=0.2 \mathrm{~m} / \mathrm{s}$. The reason for this is discussed in detail in Sect. 3. However, we emphasize that the choice does not limit the validity of our conclusions, since the obtained results show a coherent behavior that can be extrapolated to smaller updraft velocities.

Varied model parameters describing the physico-chemical properties of the Aitken mode particles are shown Table 2. Our focus is on particles that are able to act as CCN at supersaturations characteristic for clouds formed in continental background areas, and we have utilized available empirical data in choosing the value ranges over which these parameters vary. Attributing specific probabilities to different parameter values is not, however, possible at the present due to large gaps in the current knowledge regarding the statistical distribution of the properties of atmospheric Aitken mode particles. Rather, only a value range can be ascertained with confidence. Accordingly, it was assumed that all the varied parameters are distributed uniformly, excluding $C N$ and $\alpha$ of which values span several orders of magnitude. In order to better account for the larger variability, it was assumed that the logarithms of $C N$ and $\alpha$ have uniform distributions.

The parameters listed in Table 2 can be divided into two groups: those describing the modal properties of Aitken mode particles (first three parameters) and those related to their chemical composition (last six parameters). The parameters belonging to the first group are the number concentration of Aitken mode particles, $C N$, and the mean size and geometric standard deviation of the Aitken mode, $D_{m}$ and $\sigma_{g}$, respectively. The value ranges of these parameters are chosen according to the particle size distribution measurements conducted in continental background areas (e.g. Tunved et al., 2003) and represent thus observationally constrained value ranges. Here we would like to point out that one factor influencing the number of cloud droplets formed is the particle mixing state (Rissman et al., 2006). The issue 
is relevant since the water solubility of the particle matter is modeled here using more than one component by dividing the particle dry mass into soluble and insoluble fractions. The mixing state of a particle population is a qualitative concept, however, and as such cannot be incorporated into the current framework. Therefore it is assumed that particles are internally mixed, but we acknowledge the fact that the effect of varying particle mixing state is not captured by our approach.

The varied parameters related to the particle chemical composition include the soluble mass fraction, density and number-averaged molecular weight of the matter comprising the Aitken mode particles, $\varepsilon, \rho$, and $M W_{\text {avg }}$, respectively. These parameters include also the so-called "effective" Van't Hoff factor, $v \Phi$, which is the product of the osmotic coefficient of the solute, $\Phi$, and the number of ions resulting from dissociation of a solute molecule in the aqueous phase, $v$. The remaining two parameters in this group are the surface tension of the Aitken mode particles and droplets formed on them, $\sigma_{s}$, and the mass accommodation coefficient of water onto the surfaces of the Aitken mode particles and resulting droplets, $\alpha$.

A proper choice of the value ranges of the last six parameters listed in Table 2 is problematic due to the organic aerosol component which is not completely characterized at the present. Therefore it was decided to make several sensitivity studies with the same approach but using different value ranges for the most poorly-constrained parameters. The first sensitivity study can be viewed conservative because the full variability in the chemical composition of atmospheric aerosols is not accounted for. We term this scenario as "BASE". Since this scenario may underestimate the importance of the particle chemical composition, we performed two additional sets of sensitivity studies, called "MACRO" and "FILM". In these scenarios, we adopted larger value ranges for certain input parameters.

The "BASE" scenario is based on the following assumptions: particles do not contain 1) macromolecules having a large molecular weight $(>250 \mathrm{~g} / \mathrm{mol}), 2)$ compounds having more than two carboxylic groups, 3) surface-active compounds that decrease the value of $\sigma_{s}$ more than roughly $30 \%$, or 4) surface-active compounds that are able to form a thick film onto the particle/droplet surface and thereby reduce the value of $\alpha$ below the range that has been reported for pure water surfaces $(\sim 0.01-1.0$, see Laaksonen et al., 2005, and references therein). Regarding the last assumption, it should be pointed out that the value range represents the variation in the whole data set, and that the recent droplet growth studies conducted at carefully controlled conditions indicate that the value is close to unity (Laaksonen et al., 2005; Wagner et al., 2006). In particular, smaller values measured on heterogeneous uptake experiments may be prone to errors due to ill-defined boundary conditions (Kulmala and Wagner, 2001; Laaksonen et al., 2005) and therefore the real uncertainty associated with the value of $\alpha$ is probably smaller than our choice would suggest. As seen later, however, adopting such a large value range does not affect our conclusions.

Examples of organic compounds that meet the abovementioned criteria are various alcohols, polyols, ketones, aldehydes and acids containing one or two functional groups (Saxena and Hildemann, 1996). The maximum allowed reduction in $\sigma_{s}$ is consistent with surface tension measurements of atmospherically relevant organics at relatively dilute solutions (Shulman et al., 1996; Facchini et al., 2000; Tuckermann and Cammenga, 2004; Hyvärinen et al., 2006; Salma et al., 2006; Svenningsson et al., 2006). It should be noted that surface tension is a dynamic parameter which depends on the particle size and relative humidity (Ervens et al., 2005; Asa-Awuku and Nenes, 2007; Dinar et al., 2006). We have assumed, however, that the value of $\sigma_{s}$ is constant during a model run, i.e. it does not depend on the particle/droplet size or its composition. This allows for assessing unambiguously the importance of $\sigma_{s}$ in the considered value range. Because particles dilute rapidly during cloud formation, the surface tension of particles and droplets approaches that of water as the cloud develops. Consequently, the assumption regarding constancy of $\sigma_{s}$ overestimates the effect of organics to the particle/droplet surface tension to some extent. It should be further noted that the value of $\alpha$ is kept constant in a similar manner even though it is expected to depend on the particle/droplet size and composition (e.g. Feingold and Chuang, 2002). As in the case of the surface tension, the estimated importance of $\alpha$ represents consequently an upper limit.

The soluble mass fraction, $\varepsilon$, in atmospheric Aitken mode particles is poorly constrained as well, and indirect measurements on the chemical composition of sub- $100 \mathrm{~nm}$ particles suggest that $\varepsilon$ can be even lower than the minimum value chosen here, 0.25 (Svenningsson et al., 1997; Ehn et al., 2007). However, given that the model solute compound in the cited studies was ammonium sulfate, soluble fractions $<0.25$ translate to critical supersaturations $>0.5 \%$ for Aitken-mode sized particles. The range is clearly higher than the maximum supersaturations reached at continental environments with updraft velocities $<1.0 \mathrm{~m} / \mathrm{s}$ (Seinfeld and Pandis, 1998), and therefore such particles cannot be regarded as "potential" CCNs under conditions relevant to this study. Regarding the particle dry density, $\rho$, the range chosen here spans the range expected for atmospheric aerosols. Taken together, the discussed choices limit the value ranges of $M W_{\text {avg }}, \rho, v \Phi, \sigma_{s}$ and $\alpha$ to those shown in Table 2.

The second sensitivity study, the "MACRO" scenario, differs from the "BASE" scenario by larger value ranges applied for the parameters $M W_{\text {avg }}, \nu \Phi, \sigma_{s}$ and $\alpha$ (Table 2). The larger value ranges reflect the findings that atmospheric aerosols, including Aitken mode particles, may contain polyfunctional compounds with large molecular weights and ability to act as effective surfactants (Facchini et al., 1999; Graber and Rudich, 2006, and references therein). The upper limit for $M W_{\mathrm{avg}}, 600 \mathrm{~g} / \mathrm{mol}$, is chosen according to 


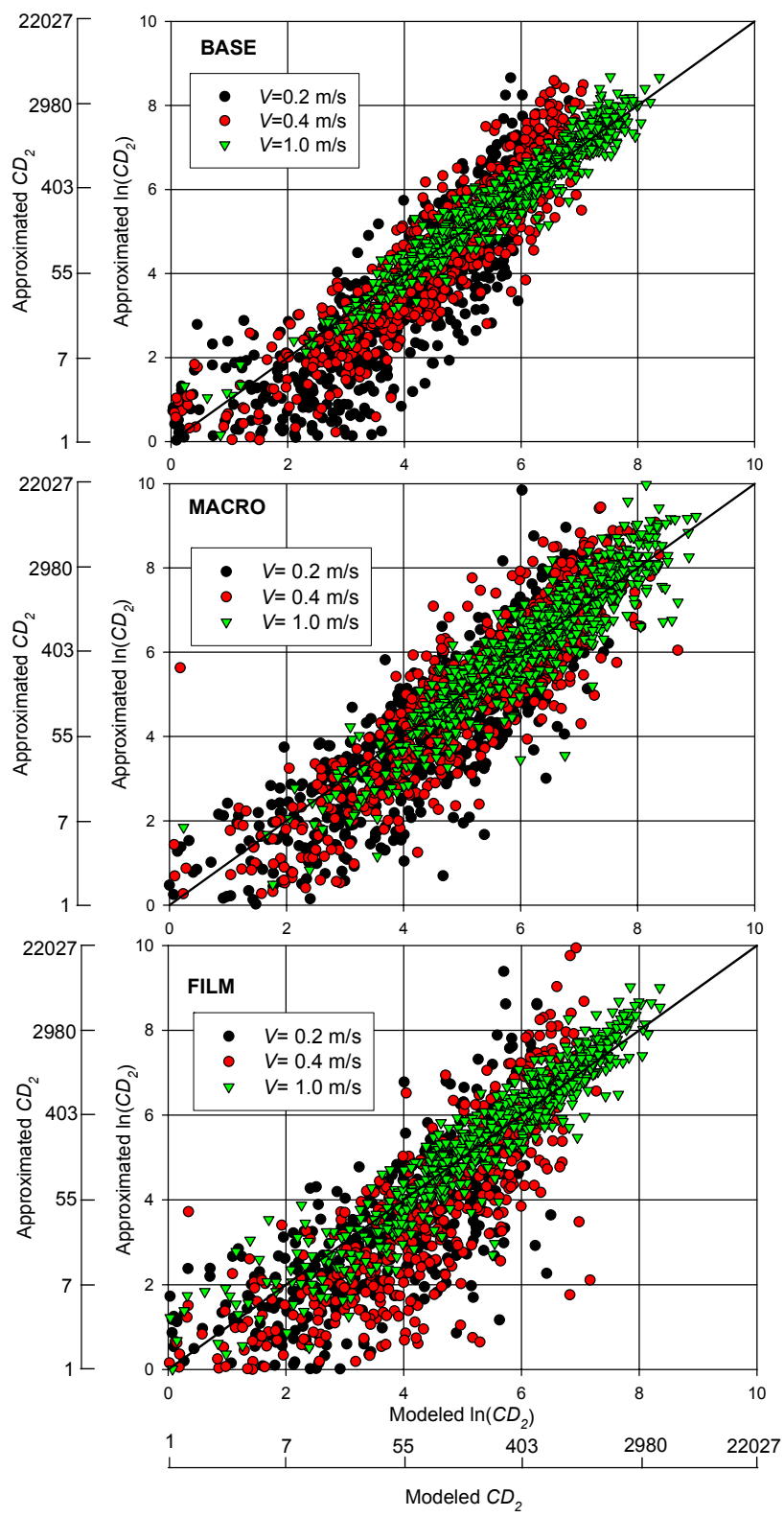

Fig. 1. A comparison of $\ln \left(C D_{2}\right)$ predicted by the adiabatic air parcel model and by the corresponding PCEs. The scenario is shown in each plot, and the updraft velocity $(V)$ is shown in the legend. Furthermore, 1:1 line is added to each plot to guide the eye.

experimental information on the number-averaged molecular weight of humic-like substances (HULIS) extracted from atmospheric aerosols (Dinar et al., 2006). Although several studies indicate that larger macromolecules with MWs over $1000 \mathrm{~g} / \mathrm{mol}$ can be present in aerosols (Graber and Rudich, 2006, and references therein), we use a smaller limit for the following reasons. First, the studies reporting the large MWs are mainly smog-chamber experiments in which conditions may not be entirely representative to those in the atmosphere (Graber and Rudich, 2006). Second, the available evidence seems to suggest that the MW distributions have a maximum value below $600 \mathrm{~g} / \mathrm{mol}$ in these experiments (Graber and Rudich, 2006). Since we assume only a single solute in the AAPM, the use of larger solute MWs may thus grossly overestimate the atmospherically realistic range of numberaveraged MW, the fundamental quantity here (Dinar et al., 2006), and may therefore also overestimate the variability arising from MW. For these reasons, the value of $M W_{\text {avg }}$ is not varied by more than one order of magnitude. The maximum value of $v \Phi$, in turn, is based on the properties of a standard Fulvic acid compound that has been used in several studies as a model compound for aerosol-bound polyfunctional compounds (Mircea et al., 2002; Nenes et al., 2002). Finally, the lower limit for $\sigma_{s}, 0.02 \mathrm{~N} / \mathrm{m}$, is chosen according to the estimate of Ervens et al. (2005) for the maximum reduction of the droplet surface tension due to the presence of organics at relative humidities close to $100 \%$.

The third scenario, "FILM", differs from the "BASE" scenario only by the larger value range of $\alpha$ (Table 2). The minimum values adopted here are based on available experimental evidence suggesting that the mass accommodation coefficient of water on atmospheric aerosols can be as low as $10^{-5}$ (Chuang, 2003, and references therein). The possible value range spans thus five orders of magnitude. However, in the discussed scenario, "FILM", the minimum value of $\alpha$ was decreased only down to $10^{-3}$, and the reason for not using smaller values is discussed in Sect. 3.2.3.

\subsection{Validation of the method}

The validity of our approach was evaluated as follows. For each PCE generated, we performed 750 additional AAPM simulations, in which the considered input parameters were varied randomly according to their probability distributions. The results were compared with the corresponding predictions of the PCEs. Based on the AAPM calculations, probability density functions (PDFs) for $C D_{2}$ were then constructed, and these PDFs were compared with PDFs obtained by sampling from the corresponding PCEs. Finally, the PCE and model-based expected values and variances of $\ln \left(C D_{2}\right)$ were compared.

\section{Results}

\subsection{Performance of the PCEs}

Figure 1 shows a comparison of the true model output and corresponding PCE-based predictions for $\ln \left(C D_{2}\right)$. Further, the corresponding coefficients of determinations, $R^{2}$, are displayed in Table 3. The comparison has been made for $\ln \left(C D_{2}\right)$ and not for $C D_{2}$, since $\ln \left(C D_{2}\right)$ is the approximated model output. Results are shown for all the three scenarios and for three updraft velocities $(\mathrm{V}=0.2,0.4$ and $1.0 \mathrm{~m} / \mathrm{s}$ ). The average maximum supersaturations in the AAPM calculations for these three updraft velocities were around 0.12 , 
Table 3. The average maximum supersaturation reached during simulations, coefficients of determination, $R^{2}$, relative errors in the expected values and total variances of $\ln \left(C D_{2}\right)\left(E\left[\ln \left(C D_{2}\right)\right]\right.$ and $\operatorname{Var}\left[\ln \left(C D_{2}\right)\right]$, respectively) for updraft velocities $V=0.2,0.4 \mathrm{and} 1.0 \mathrm{~m} / \mathrm{s}$.

\begin{tabular}{lccccccccc}
\hline & \multicolumn{3}{c}{ "BASE" } & \multicolumn{3}{c}{ "MACRO" } & \multicolumn{3}{c}{ "FILM" } \\
\hline$V(\mathrm{~m} / \mathrm{s})$ & 0.2 & 0.4 & 1.0 & 0.2 & 0.4 & 1.0 & 0.2 & 0.4 & 1.0 \\
Average $S S_{\max }(\%)$ & 0.12 & 0.16 & 0.28 & 0.12 & 0.15 & 0.27 & 0.12 & 0.17 & 0.29 \\
$R^{2}$ & 0.78 & 0.83 & 0.94 & 0.8 & 0.77 & 0.83 & 0.79 & 0.81 & 0.82 \\
Error in $E\left[\ln \left(C D_{2}\right)\right](\%)$ & 6 & 0.8 & 0.6 & 1 & 0.6 & 0.3 & 12 & 8 & 2 \\
Error in $\operatorname{Var}\left[\ln \left(C D_{2}\right)\right](\%)$ & 5 & 11 & 1 & 10 & 3 & 3 & 14 & 0.3 & 15 \\
\hline
\end{tabular}

0.16 , and $0.28 \%$, respectively, regardless of the scenario. These values compare favorably with estimated supersaturations reached in continental clouds (Pruppacher and Klett, 1997; Cantrell et al., 1999).

As can be seen from Fig. 1, the PCEs approximate the true model output generally well in all scenarios, showing that the algorithm for determining PCEs was properly implemented. The corresponding $R^{2}$ values ranged between 0.78 and 0.94 (Table 3). Figure 1 and Table 3 show also that the degree of agreement is fairly independent of the scenario. Furthermore, the largest errors take place for the smallest updraft velocity, $0.2 \mathrm{~m} / \mathrm{s}$, and the degree of agreement generally increases with increasing $V$. This result can be explained in the following way. At low updraft velocities, no cloud droplets are predicted to be formed on Aitken mode particles in large parts of the parameter space due to low supersaturations reached during an air ascent. On the other hand, small changes in the input parameter values may produce notable changes in $C D_{2}$, such that $C D_{2}$ increases or decreases steeply with the changing value of the parameter. Thus $C D_{2}$ exhibits a "threshold behaviour" that is difficult to be captured using a polynomial approximation, and this is also the reason why updraft velocities lower than $0.2 \mathrm{~m} / \mathrm{s}$ are not explicitly considered. In contrast, activation of Aitken mode particles to cloud droplets is more favorable at higher updraft velocities where $C D_{2}$ also tends to be less sensitive to the input parameter values.

For the purposes of this study, it is more important that the statistical features of the model output are produced with a sufficient accuracy than that a good approximation for the true model output is obtained in every point of the parameter space. Therefore we compared also the PCE-based PDFs of $C D_{2}$ with corresponding ones generated from the true model output. Figure 2 shows the comparison for two updraft velocities, $V=0.2$ and $1.0 \mathrm{~m} / \mathrm{s}$ which include cases with the least and largest degree of agreement (Table 3). As can be seen, a quantitative agreement is reached in most cases: the PCEs produce the basic characteristics, such as the shape and peak, of the PDFs describing the true model output. For cases with $V=0.2 \mathrm{~m} / \mathrm{s}$, however, the PCM-based PDFs are biased towards smallest $\left(<10 \mathrm{~cm}^{-3}\right)$ and largest $\left(>1000 \mathrm{~cm}^{-3}\right)$ values of $C D_{2}$ as compared to the PDFs of the true model out- put. In addition, the peak of the PDF is notably shifted to smaller concentrations in the "BASE" and "FILM" scenarios. These discrepancies are caused by the "threshold" behavior discussed above. However, the agreement improves rapidly when $V$ increases and as Fig. 2 illustrates, a very good agreement is reached for higher updraft velocities.

The PCE and model-based expected values and variances of $\ln \left(C D_{2}\right), E\left[\ln \left(C D_{2}\right)\right]$ and $\operatorname{Var}\left[\ln \left(C D_{2}\right)\right]$, respectively, were also compared, and the relative errors in predicting $E\left[\ln \left(C D_{2}\right)\right]$ and $\operatorname{Var}\left[\ln \left(C D_{2}\right)\right]$ are shown in Table 3. As seen, $E\left[\ln \left(C D_{2}\right)\right]$ is reproduced accurately in most of cases, and the maximum error is $12 \%$. Errors in $\operatorname{Var}\left[\ln \left(C D_{2}\right)\right]$ are generally slightly larger, the maximum error being $15 \%$.

Results shown in Figs. 1 and 2 and in Table 3 provide a comprehensive characterization of the accuracy of the PCEs generated. To summarize, in spite of the biases exhibited by the PCEs at low updraft velocities, the agreement is sufficient to warrant the conclusions based on the sensitivity analysis which is discussed next.

\subsection{Sensitivity study}

After the PCEs were generated, the contribution of each varied input parameter (listed in Table 2) to the total variance of the model output was calculated using Eq. (5). As discussed in Sect. 2.3, these input parameters can be divided into two groups: those related to the modal properties (first three parameters in Table 2) and those related to the chemical composition of the Aitken mode particles (last six parameters in Table 2). Here we call these parameters physicsand chemistry-related parameters, respectively. With an aim to find out which of them cause most of the variance of the model output, Fig. 3 shows the relative importance of the particle size distribution versus the particle chemical composition for all three scenarios.

Common to all the results is that the importance of the particle chemical composition decreases as $V$ increases. This feature is consistent with the results of Ervens et al. (2005) who predicted that the cloud droplet number concentration becomes less sensitive to the particle chemical composition as the updraft velocity increases. Also, the net contribution of the physics-related parameters to the total variance becomes 

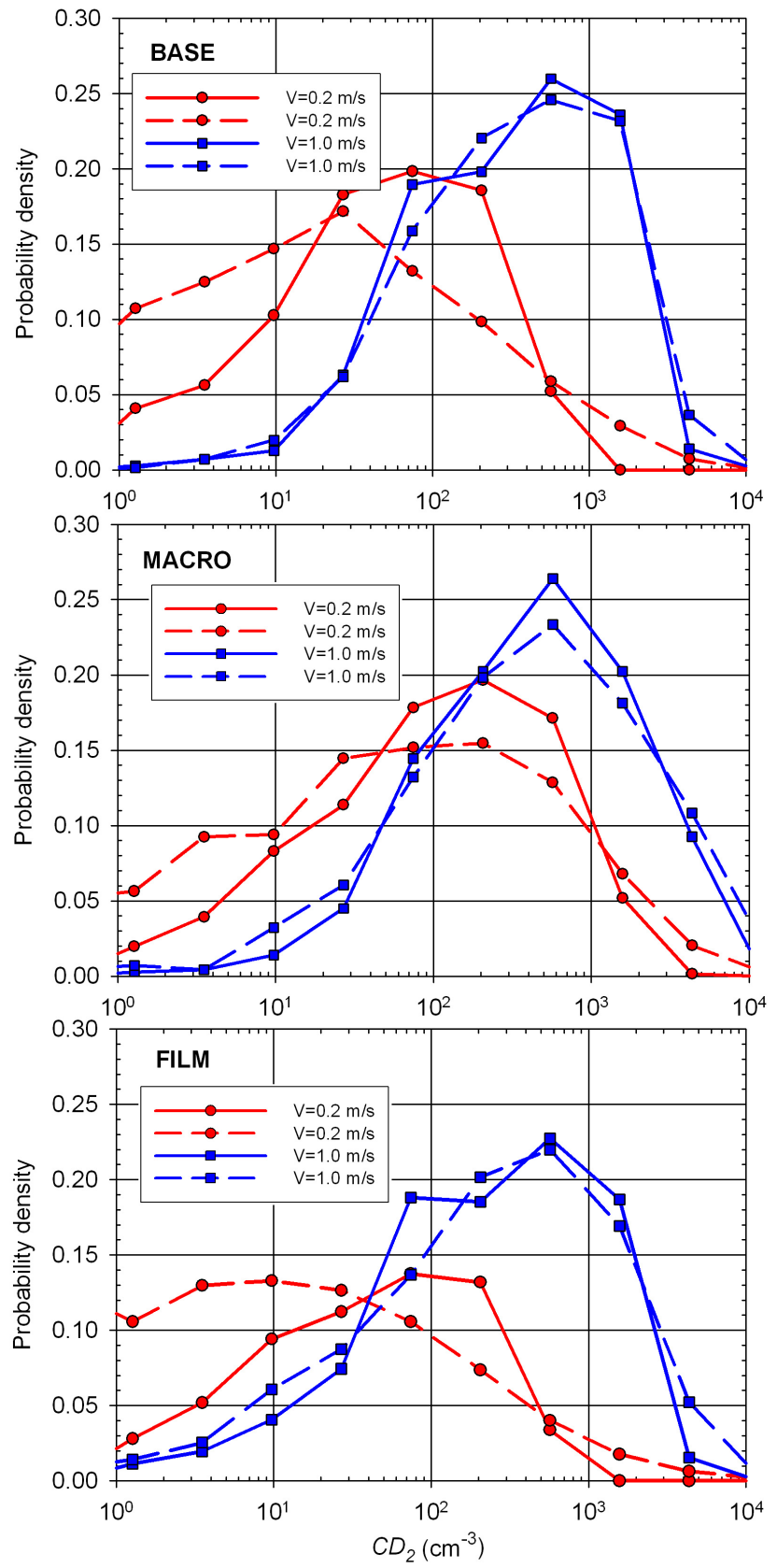

Fig. 2. The probability density functions representing the original model output (solid lines) and samples from the PCEs (dashed lines). The scenario is shown in each plot, and the updraft velocity $(V)$ is shown in the legend.

larger than that of the chemistry-related parameters at updraft velocities of $\sim 0.3$ and $\sim 0.9 \mathrm{~m} / \mathrm{s}$ in the "MACRO" and "FILM" scenarios, respectively. In the "BASE" scenario, the physics-related parameters dominate the total variance of the model output regardless of the updraft velocity. The larger roles of the particle chemical composition in the "MACRO" and "FILM" scenarios are mainly due to larger value ranges

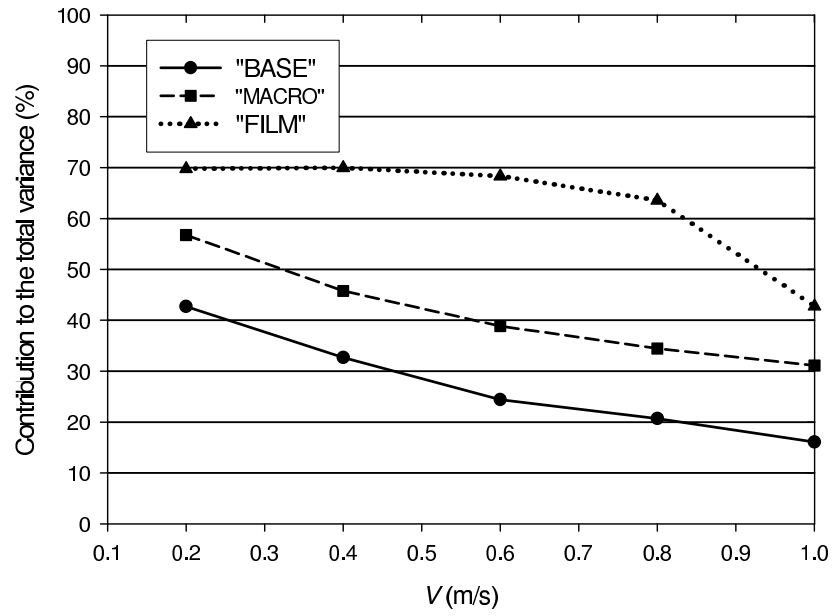

Fig. 3. The net contribution of chemistry-related parameters to the total variance of the model output as a function of the updraft velocity, $V$. The scenario is indicated in the legend.

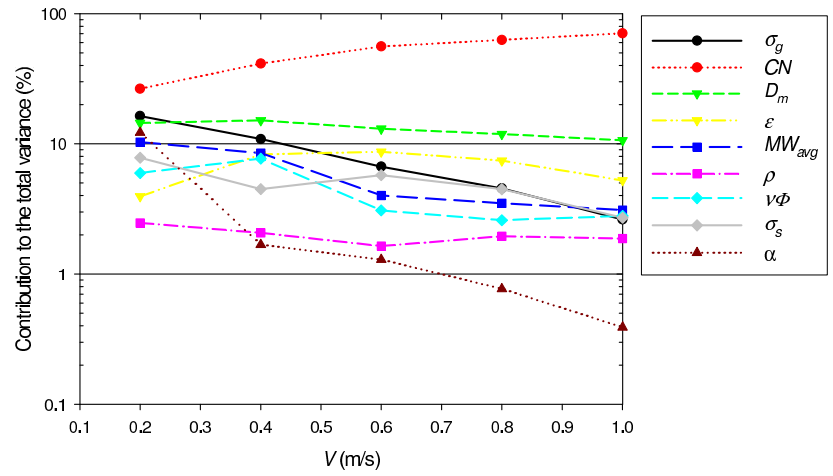

Fig. 4. The contributions of the uncertain model parameters to the total variance of the model output as a function of the updraft velocity, $V$, for the "BASE" scenario. The model parameters are indicated in the legend.

adopted for the surface tension and mass accommodation coefficient, respectively (Table 2), as will be shown below. Overall, these results suggest that the chemical composition can be as important as the physical properties regarding the cloud-nucleating ability of Aitken mode particles in the continental background areas.

Next we elucidate which individual parameters are behind the features displayed in Fig. 3. Figures 4, 5 and 6 show the contribution of the individual parameters (listed in Table 2) to the total variance of the model output for the "BASE", "MACRO" and "FILM" scenarios, respectively. Furthermore, the average contribution of each parameter is shown in Table 4 for all the scenarios. The averaging is performed over the considered updraft velocities with the same weight given for each value of $V$. 


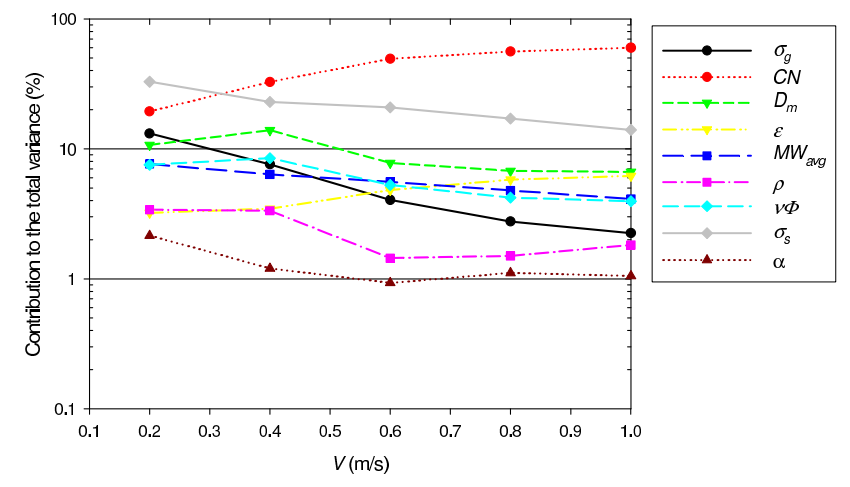

Fig. 5. Same as Fig. 4, but for the "MACRO" scenario.

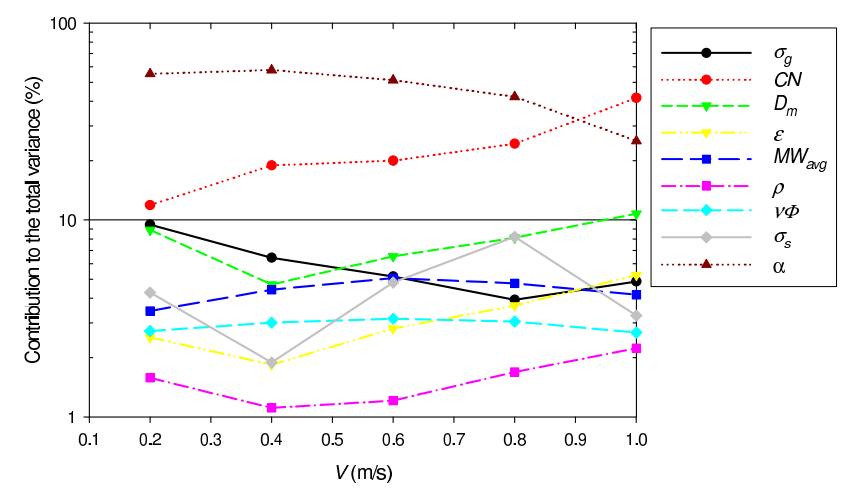

Fig. 6. Same as Fig. 4, but for the "FILM" scenario.

\subsection{1 "BASE" scenario}

The "BASE" scenario is considered first. Figure 4 shows that the physics-related parameters $C N, D_{m}$ and $\sigma_{g}$, dominate the total variance of the model output, $C N$ being the most important parameter in this respect. It is also seen that the relative importance of $C N$ increases with increasing $V$. This is due to larger maximum supersaturations reached at higher updraft velocities which allows for a larger fraction of Aitken mode particles to form cloud droplets. Consequently, the value of $C D_{2}$ reflects that of $C N$ at higher updraft velocities. This is also the main reason for the increasing importance of the physics-related parameters with increasing $V$ (Fig. 3).

Figure 4 shows also that the relative importance of $\sigma_{g}$ decreases with increasing $V$. This is because typically only a small fraction of the Aitken mode particles, i.e. particles belonging to the "tail" which extends to larger sizes, are able to form cloud droplet at low updraft velocities. Under these conditions, increasing $\sigma_{g}$ increases the number of particles in the "tail" and hence also $C D_{2}$ given that other factors remain constant. At higher updraft velocities, however, $C D_{2}$ becomes less sensitive to $\sigma_{g}$ since larger fractions of the Aitken mode particles generally activate. To illustrate this point, let us consider an extreme case in which exactly half of the Aitken mode particles form cloud droplets and the mode
Table 4. Average contributions of the uncertain input parameters to the total variance of the model output (in percentages). Averaging is performed over all considered updraft velocities for a scenario with equal weight given for each case. Three largest sources of the variance are indicated with bold.

\begin{tabular}{lccc}
\hline Abbreviation & "BASE" & "MACRO" & "FILM" \\
\hline$\sigma_{g}$ & $\mathbf{8}$ & 6 & 6 \\
$C N$ & $\mathbf{5 1}$ & $\mathbf{4 3}$ & $\mathbf{2 3}$ \\
$D_{m}$ & $\mathbf{1 3}$ & $\mathbf{9}$ & $\mathbf{8}$ \\
$\varepsilon$ & 7 & 5 & 3 \\
$M W_{\text {avg }}$ & 6 & 6 & 4 \\
$\rho$ & 2 & 2 & 2 \\
$\nu \Phi$ & 4 & 6 & 3 \\
$\sigma_{S}$ & 5 & $\mathbf{2 2}$ & 4 \\
$\alpha$ & 3 & 1 & $\mathbf{4 6}$ \\
\hline
\end{tabular}

is internally mixed. In this situation, $C D_{2}$ does not depend on $\sigma_{g}$ at all, provided that other factors do not change with changing $\sigma_{g}$. When more than half of the Aitken mode particles nucleate to cloud droplets, the sensitivity of $C D_{2}$ to $\sigma_{g}$ starts to increase again. However, this does not take place in most of the calculations which together with the other factors discussed here explains the feature.

The relative importance of the third physics-related parameter, $D_{m}$, decreases slightly with increasing $V$. The decrease is because the minimum particle diameter decreases with increasing maximum supersaturations and hence the particle size plays smaller role at higher updraft velocities. Another interesting result is that $\sigma_{g}$ and $D_{m}$ have both approximately equal importance at $V<0.4 \mathrm{~m} / \mathrm{s}$. This suggests that the shape of the Aitken mode has also to be accounted for when predicting the contribution of sub- $100 \mathrm{~nm}$ particles to cloud droplet concentrations at regimes with low updraft velocities.

The parameters $\varepsilon, M W_{\text {avg }}$ and $\sigma_{s}$ are the three most important chemistry-related parameters, as can be seen from Fig. 4 and Table 4 , with roughly equal contribution from each parameter. The result that $\varepsilon$ and $M W_{\text {avg }}$ have similar importance is intuitive since both of them are varied over a factor of four to a good approximation (Table 2) and the number of dissolved molecules, which determines the Raoult term in the Koehler equation, scales with these two parameters (Seinfeld and Pandis, 1998). The contributions of $\varepsilon, M W_{\mathrm{avg}}$ and $\sigma_{s}$ to the total variance of the model output is, however, smaller than those of $C N$ and $D_{m}$. More generally, the net contribution of the chemistry-related parameters is smaller than that of physics-related parameters (Fig. 3), which implies that if the chemical composition of the atmospheric Aitken mode particles varies in the range characteristic to the "BASE" scenario, the modal properties have a larger overall effect on the cloud-nucleating ability of the Aitken mode particles than the chemical composition. Regarding the other 
varied parameters, it is worth noting that $\alpha$ contributes only marginally to the total model variance, except in the case with the lowest updraft velocity. Additional calculations revealed that $\alpha$ contributes 6 and 3\% to the total variation of the model output for $V=0.25$ and $0.3 \mathrm{~m} / \mathrm{s}$, respectively. The contribution of $\alpha$ thus reduces from 12 to $3 \%$ when $V$ increases from 0.2 to $0.3 \mathrm{~m} / \mathrm{s}$, and such a drastic change is not intuitive in view of the fact that the relative contributions of other varied parameters display a coherent behavior. Moreover, the feature is not seen in the "MACRO" scenario (see below) even though $\alpha$ has the same value range (Table 1). We thus conclude that the PCEs consistently overestimate the role of $\alpha$ at updraft velocities $<0.3 \mathrm{~m} / \mathrm{s}$.

\subsection{2 "MACRO" scenario}

The "MACRO" scenario differs from the "BASE" scenario by larger value ranges adopted for $M W_{\text {avg }}, \nu \Phi$ and $\sigma_{s}$ (Table 2). The difference is also reflected in the results: the chemical composition of the Aitken mode particles is more important in the "MACRO" scenario than in the "BASE" scenario (Fig. 3). As seen from Fig. 5, this is mainly due to $\sigma_{s}$ which is the most important parameter regarding the total variance of the model output at $V<0.3 \mathrm{~m} / \mathrm{s}$. The contribution of $\sigma_{s}$ is exceeded by that of $C N$ at larger updraft velocities, and the reason for the growing importance of $C N$ is the same as in the "BASE" scenario discussed above. The results for "MACRO" and "BASE" have also other common features: the importance of $\sigma_{g}$ decreases strongly with increasing $V$. It is further seen that the parameter $C D_{2}$ is rather insensitive to $\alpha$ and $\rho$, but exhibits notable sensitivity to $D_{m}$ regardless of the updraft velocity. The parameters $\varepsilon, M W_{\text {avg }}$ and $\nu \Phi$ make similar contributions to the total variance of the model output, but the relative importance of these three parameters shows some variation with the updraft velocity.

To summarize, the largest change compared to the "BASE" scenario is the increased role of the surface tension, which leads to the following conclusion: if particlephase organics do not decrease the surface tension of Aitken mode particles by more than approximately $30 \%$, the variation in the model output due to the varying surface tension is comparable to that caused by the varying water-soluble mass fraction and molecular weight of the organics. However, a sufficient presence of extremely surface-active organics may cause substantial uncertainties in predictions concerning the cloud-nucleating ability of Aitken mode particles.

\subsection{3 "FILM" scenario}

The contributions of the individual input parameters to the total variance of the model output are shown in Fig. 6 for the "FILM" scenario (see also Table 4 for the average values). The most notable feature of the results is that $\alpha$ makes the largest contribution to the total variance of the model output at updraft velocities of approximately $<0.9 \mathrm{~m} / \mathrm{s}$. It is also seen that only $\alpha$ and $C N$ contribute more than $10 \%$ to the total variance, $C N$ becoming more important at larger updraft velocities. The relative contributions of the other model parameters are similar to those in the "BASE" scenario and are not described explicitly here. We note, however, that the contribution of $\sigma_{s}$ varies between 3 and $8 \%$ in a manner that is difficult to interpret. In any case, it is clear that the importance of $\sigma_{s}$ is much smaller than those of $\alpha$ and $C N$.

The most important conclusion following from our results is that when the value of the parameter $\alpha$ is in the range between $10^{-2}$ and unity, it forms a relatively small source of uncertainty in the cloud droplet predictions. In contrast, if $\alpha$ varies more than two orders of magnitude at conditions close to reaching saturation, the variability translates to large uncertainties regarding the ability of atmospheric sub- $100 \mathrm{~nm}$ particles to form cloud droplets. In comparison, Chuang (2006) predicted that the cloud droplet formation exhibits large sensitivity to $\alpha$ when the value of $\alpha$ is below a critical value that ranges between 0.1 and $10^{-3}$ depending on the droplet size.

In view of the fact that the minimum value of $\alpha$ can potentially be even lower than the value applied here (see Sect. 2.3.), it can be asked how results would change by decreasing the minimum value of $\alpha$ further by one or two orders of magnitude. To this end, we performed also calculations using $10^{-4}$ as a minimum value for $\alpha$, but the agreement between the PCEs and the true model output was notably worse compared with the results for the three scenarios considered here. This was probably due to complicated cloud formation dynamics caused by extremely small values of $\alpha$. In view of this, it is expected that the importance of $\alpha$ increases even further with increasing value range of $\alpha$.

\section{Discussion and conclusions}

The present study attempts to identify and rank the physicochemical properties of Aitken mode particles that determine the cloud-nucleating ability of these particles in continental background areas. The approach is based on performing calculations with an adiabatic air parcel model and analyzing the model output with the probabilistic collocation method (PCM). The PCM is a tool for "global" sensitivity analysis and it propagates uncertainty or variability in the input parameter values to the model output. Here the model output of interest is the number concentration of cloud droplets formed on Aitken mode particles, $C D_{2}$, as a function of the updraft velocity, and the varied model parameters were those describing the modal and chemical properties of the Aitken mode particles.

The relative roles played by the particle size distribution and chemical composition in determining the cloudnucleating ability of atmospheric particles is a subject of intense research at the present (McFiggans et al., 2006; Dusek et al., 2006; Ervens et al., 2007), and the results of our study 
have also implications on this issue. First, unless the particle surface tension or mass accommodation coefficient of water is strongly reduced due to the presence of surface-active organics, the parameters describing the size distribution are generally more important than the particle chemical composition. In the absence of such compounds, the chemical composition may have roughly an equal importance with the size distribution only at low updraft velocities characterized by maximum supersaturations $<0.1 \%$ (Fig. 4 and Table 3). Furthermore, the largest source of variance of the model output is generally the particle number concentration, followed by the particle size. Second interesting result is that the shape of the particle mode, characterized by the geometric standard deviation (GSD), can be as important as the mean size of the mode at low updraft velocities. This suggests that using a prescribed value for the GSD (see Vignati et al., 2004, for example) might cause errors to the predicted effect of sub$100 \mathrm{~nm}$ sized particles on the cloud droplet number concentrations.

The performed sensitivity analysis revealed that the variability of the particle chemical composition may dominate the total variance of $C D_{2}$ if: 1) the value of $\alpha$ varies three orders of magnitude or more, or 2) the particle surface tension varies more than roughly $30 \%$ under conditions close to reaching saturation. Due to the simplified numerical treatment of the surface tension and mass accommodation coefficient in the model, this estimate probably represents an upper limit of the importance of these two parameters. Nevertheless, the results provide motivation for experimental studies aiming to find out if $\alpha$ may reduce below $10^{-2}$ or if the surface tension may reduce below $\sim 0.05 \mathrm{~N} / \mathrm{m}$ for aerosols comprising of atmospherically relevant mixtures at relevant dilution levels.

The largest sources of uncertainty in the conclusions presented above arise from poorly characterized chemical composition of sub- $100 \mathrm{~nm}$ atmospheric particles. When more information on the particle chemical composition emerges, however, it can be utilized to constrain the probability distributions of the corresponding model parameters. Consequently, the accuracy of the sensitivity analysis will improve (Tatang et al., 1997). We also expect that the results of the study are generally applicable to atmospheric conditions where supersaturations reached during cloud formation are of similar magnitude than in simulations considered here. On the other hand, the results are probably not applicable to polluted conditions where supersaturations are considerable lower. Because of the low supersaturations, however, the contribution of Aitken mode is expected to be insignificant in such areas.

Acknowledgements. The work has been supported by the Academy of Finland and European Union (project 018332). One of the authors (T. Anttila) acknowledges the financial support from the Emil Aaltonen Foundation.

Edited by: M. Kulmala

\section{References}

Anttila, T. and Kerminen, V.-M.: Influence of organic compounds on cloud droplet activation - a model investigation considering the volatility, water-solubility and surface activity of organic matter, J. Geophys. Res., 107, 4662, doi:10.1029/2001JD001482, 2002.

Asa-Awuku, A. and Nenes, A.: The Effect of Solute Dissolution Kinetics on Cloud Droplet Formation: 1. Extended Köhler theory, J. Geophys. Res.-Atmos., in press, 2007.

Calbó, J., Pan, W., Webster, M., Prinn, R., and McRae, G.: Parameterization of Urban Sub-Grid Scale Processes in Global Atmospheric Chemistry Models, J. Geophys. Res., 103, 3437-3452, 1998.

Cantrell, W., Shaw, G., and Benner, R.: Cloud properties inferred from bimodal number distributions, J. Geophys. Res., 104, 27 615-27 624, 1999.

Chuang, P. Y.: Measurement of the timescale of hygroscopic growth for atmospheric aerosols, J. Geophys. Res., 108, 4282, doi:10.1029/2002JD002757, 2003.

Chuang, P. Y.: Sensitivity of cloud condensation nuclei activation processes to kinetic parameters, J. Geophys. Res., 111, D09201, doi:10.1029/2005JD006529, 2006.

Dinar, E., Taraniuk, I., Graber, E., Katsman, S., Moise, T., Anttila, T., Mentel, T., and Rudich, Y.: Cloud Condensation Nuclei properties of model and atmospheric HULIS, Atmos. Chem. Phys., 6, 2465-2482, 2006,

http://www.atmos-chem-phys.net/6/2465/2006/.

Dusek, U., Frank, G. P., Hildebrandt, L., Curtius, J., Schneider, J., Walter, S., Chand, D., Drewnick, F., Hings, S., Jung, D., Borrmann, S., and Andreae, M. O.: Size matters more than chemistry for cloud-nucleating ability of aerosol particles, Science, 312, 1375-1378, 2006.

Ehn, M., Petäjä, T., Aufmhoff, H., Aalto, P., Hämeri, K., Arnold, F., Laaksonen, A., and Kulmala, M.: Hygroscopic properties of ultrafine aerosol particles in the boreal forest: diurnal variation, solubility and the influence of sulfuric acid, Atmos. Chem. Phys., 7, 211-222, 2007,

http://www.atmos-chem-phys.net/7/211/2007/.

Ervens, B., Feingold, G., and Kreidenweis, S. M.: Influence of water-soluble organic carbon on cloud drop number concentration, J. Geophys. Res., 110, D18211, doi:10.1029/2004JD005634, 2005.

Ervens, B., Cubison, M., Andrews, E., Feingold, G., Ogren, J. A., Jimenez, J. L., DeCarlo, P., and Nenes, A.: Prediction of cloud condensation nucleus number concentration using measurements of aerosol size distributions and composition and light scattering enhancement due to humidity, J. Geophys. Res., 112, D10S32, doi:10.1029/2006JD007426, 2007.

Facchini, M. C., Decesari, S., Mircea, M., Fuzzi, S., and Loglio, G.: Surface tension of atmospheric wet aerosol and cloud/fog droplets in relation to their organic carbon content and chemical composition, Atmos. Environ., 34, 4853-4857, 2000.

Feingold: G.: Modeling of the first indirect effect: Analysis of measurement requirements, Geophys. Res. Lett., 30(19), 1997, doi:10.1029/2003GL017967, 2003.

Feingold, G. and Chuang, P. Y.: Analysis of the infuence of film forming compounds on droplet growth: Implications for cloud microphysical processes and climate, J. Atmos. Sci., 59, 20062018, 2002. 
Graber, E. R. and Rudich, Y.: Atmospheric HULIS: How humiclike are they? A comprehensive and critical review, Atmos. Chem. Phys., 6, 729-753, 2006, http://www.atmos-chem-phys.net/6/729/2006/.

Henning, S., Rosenørn, T., D’ Anna, B., Gola, A. A., Svenningsson, B., and Bilde, M.: Cloud droplet activation and surface tension of mixtures of slightly soluble organics and inorganic salt, Atmos. Chem. Phys., 5, 575-582, 2005, http://www.atmos-chem-phys.net/5/575/2005/.

Hyvärinen, A.-P., Lihavainen, H., Gaman, A., Vairila, L., Ojala, H., Kulmala, M., and Viisanen, Y.: Surface tensions and densities of oxalic, malonic, succinic, maleic, malic, and cis-pinonic acids, J. Chem. Eng. Data, 51, 255-260, 2006.

Isukapalli, S. S.: Uncertainty analysis of transport-transformation models, PhD Thesis, New Brunswick Rutgers, New Jersey State University, New Brunswick, New Jersey, United States of America, 1999.

Kerminen, V.-M., Lihavainen, H., Komppula, M., Viisanen, Y., and Kulmala, M.: Direct observational evidence linking atmospheric aerosol formation and cloud droplet activation, Geophys. Res. Lett., 32, L14803, doi:10.1029/2005GL023130, 2005.

Kiss, G., Tombacz, E., and Hansson, H.-C.: Surface tension effects of humic-like substances in the aqueous extract of tropospheric fine aerosol, J. Atmos. Chem., 50, 279-294, doi:10.1007/s10874-005-5079-5, 2005.

Kokkola, H., Sorjamaa, R., Peräniemi, A., Raatikainen, T., and Laaksonen, A.: Cloud formation of particles containing humic-like substances, Geophys. Res. Lett., 33, L10816, doi:10.1029/2006GL026107, 2006.

Komppula, M., Lihavainen, H., Kerminen, V.-M., Kulmala, M., and Viisanen, Y.: Measurements of cloud droplet activation of aerosol particles at a clean subarctic background site, J. Geophys. Res., 110, D06204, doi:10.1029/2004JD005200, 2005.

Kulmala, M. and Wagner, P. E.: Mass accommodation and uptake coefficients - A quantitative comparison. J. Aerosol Sci., 32, 833-841, 2001.

Kulmala, M., Vehkamäki, H., Petäja, T., Dal Maso, M., Lauri, A., Kerminen, V.-M., Birmili, W., and McMurry, P. H.: Formation and growth rates of ultrafine atmospheric particles: a review of observations, J. Aerosol. Sci., 35, 143-176, 2004.

Kurten, T., Kulmala, M., Dal Maso, M., Suni, T., Reissell, A., Vehkamaki, H., Hari, P., Laaksonen, A., Viisanen, Y., and Vesala, T.: Estimation of different forest-related contributions to the radiative balance using observations in southern Finland, Bor. Env. Res., 8, 275-285, 2003.

Laaksonen, A., Vesala, T., Kulmala, M., Winkler, P. M., and Wagner, P. E.: Commentary on cloud modelling and the mass accommodation coefficient of water, Atmos. Chem. Phys., 5, 461-464, 2005 , http://www.atmos-chem-phys.net/5/461/2005/.

Lohmann, U. and Feichter, J.: Global indirect aerosol effects: a review, Atmos. Chem. Phys., 5, 715-737, 2005, http://www.atmos-chem-phys.net/5/715/2005/.

Lucas, D. D. and Prinn, R. G.: Parametric sensitivity and uncertainty analysis of dimethylsulfide oxidation in the clear-sky remote marine boundary layer, Atmos. Chem. Phys., 5, 15051525, 2005,

http://www.atmos-chem-phys.net/5/1505/2005/.

Mayer, M., Wang, C., Webster, M., and Prinn, R. G.: Linking Local
Air Pollution to Global Chemistry and Climate, J. Geophys. Res., 105, 22 869-22 896, 2000.

McFiggans, G., Artaxo, P., Baltensperger, U., Coe, H., Facchini, M. C., Feingold, G., Fuzzi, S., Gysel, M., Laaksonen, A., Lohmann, U., Mentel, T. F., Murphy, D. M., O’Dowd, C. D., Snider, J. R., and Weingartner, E.: The effect of physical and chemical aerosol properties on warm cloud droplet activation, Atmos. Chem. Phys., 6, 2593-2649, 2006, http://www.atmos-chem-phys.net/6/2593/2006/.

Menon, S.: Current uncertainties in assessing aerosol effects on climate, Ann. Rev. Environ. Resour., 29, 1-30, 2004.

Mircea, M., Facchini, M. C., Decesari, S., Fuzzi, S., and Charlson, R. J.: The influence of the organic aerosol component on CCN supersaturation spectra for different aerosol types, Tellus Ser. B, 54, 74-81, 2002.

Nenes, A., Charlson, R. J., Facchini, M. C., Kulmala, M., Laaksonen, A., and Seinfeld, J. H.: Can chemical effects on cloud droplet number rival the first indirect effect?, Geophys. Res. Lett., 29, 1848, doi:10.1029/2002GL015295, 2002.

Rissman, T. A., Nenes, A., and Seinfeld, J. H.: Chemical amplification (or dampening) of the Twomey effect: Conditions derived from droplet activation theory, J. Atmos. Sci., 61, 919-930, 2004.

Rissman, T. A., VanReken, T. M., Wang, J., Gasparini, R., Collins, D.R., Jonsson, H. H. Brechtel, F. J., Flagan, R. C., and Seinfeld, J. H.: Characterization of ambient aerosol from measurements of cloud condensation nuclei during the 2003 Atmospheric Radiation Measurement Aerosol Intensive Observational Period at the Southern Great Plains site in Oklahoma, J. Geophys. Res., 111, D05S11, doi:10.1029/2004JD005695, 2006.

Salma, I., Ocskay, R., Varga, I., and Maenhaut, W.: Surface tension of atmospheric humic-like substances in connection with relaxation, dilution, and solution pH, Geophys. Res., 111, D23205, doi:10.1029/2005JD007015, 2006.

Saltelli, A.: Sensitivity analysis: Could better methods be used?, J. Geophys. Res., 104, 3789-3793, 1999.

Saltelli, A., Tarantola, S., and Chan, K. P.-S.: A quantitative modelindependent method for global sensitivity analysis of model output, Technometrics, 41, 39-56, 1999 b.

Saxena, P. and Hildemann, L. M.: Water-soluble organics in atmospheric particles: A critical review of the literature and application of thermodynamics to identify candidate compounds, J. Atmos. Chem., 24, 57-109, 1996.

Seinfeld, J. H. and Pandis, S. N.: Atmospheric chemistry and physics: From air Pollution to climate change, John Wiley, New York, United States of America, 1998.

Shulman, M. L., Jacobson, M. C., Charlson, R. J., Synovec, R. E., and Young, T. E.: Dissolution behaviour and surface tension effects of organic compounds in nucleating cloud droplets, Geophys. Res. Lett., 23, 277-280, 1996.

Sorjamaa, R., Svenningsson, B., Raatikainen, T., Henning, S., Bilde, M., and Laaksonen, A.: The role of surfactants in Köhler theory reconsidered. Atmos. Chem. Phys., 4, 2107-2117, 2004, http://www.atmos-chem-phys.net/4/2107/2004/.

Sorjamaa, R. and Laaksonen, A.: The influence of surfactant properties on critical supersaturations of cloud condensation nuclei, J. Aerosol Sci., 37, 1730-1736, 2006.

Spracklen, D. V., Springle, K. J., Carslaw, K. S., Chipperfield, M. P., and Mann, G. P.: A global off-line model of size-resolved aerosol microphysics: I. Model development and prediction of 
aerosol processes, Atmos. Chem. Phys., 5, 2227-2252, 2005, http://www.atmos-chem-phys.net/5/2227/2005/.

Spracklen, D. V., Carslaw, K. S., Kulmala, M., Kerminen, V.-M., Mann, G. W., and Sihto, S.-L.: The contribution of boundary layer nucleation events to total particle concentrations on regional and global scales, Atmos. Chem. Phys., 6, 5631-5648, 2006, http://www.atmos-chem-phys.net/6/5631/2006/.

Stier, P. Feichter, J., Kinne, S., Kloster, S., Vignati, E., Wilson, J., Ganzeveld, L., Tegen, I., Werner,M., Balkanski, Y., Schulz, M., Boucher, O., Minikin, A., and Petzold, A.: The aerosolclimate model ECHAM5-HAM, Atmos. Chem. Phys., 5, 11251156, 2005,

http://www.atmos-chem-phys.net/5/1125/2005/.

Svenningsson, B., Hansson, H. C., Martinsson, B., Wiedensohler, A., Swietlicki, E., Cederfelt, S. I., Wendisch, M., Bower, K. N., Choularton, T. W., and Colvile, R. N.: Cloud droplet nucleation scavenging in relation to the size and hygroscopic behaviour of aerosol particles, Atmos. Environ., 31, 2463-2475, 1997.
Tatang, M., Pan, W., Prinn, R., and McRae, G.: An efficient method for parametric uncertainty analysis of numerical geophysical models, J. Geophys. Res., 102, 21 925-21 932, 1997.

Tuckermann, R. and Cammenga, H. K.: The surface tension of aqueous solutions of some atmospheric water-soluble organic compounds, Atmos. Environ., 38, 6135-6138, 2004.

Tunved, P., Hansson, H.-C., Kulmala, M., Aalto, P., Viisanen, Y., Karlsson, H., Kristensson, A., Swietlicki, E., Dal Maso, M., Ström, J., and Komppula, M.: One year boundary layer aerosol size distribution data from five nordic background stations, Atmos. Chem. Phys., 3, 2183-2205, 2003, http://www.atmos-chem-phys.net/3/2183/2003/.

Vignati, E., Wilson, J., and Stier, P.: M7: An efficient size-resolved aerosol microphysics module for large-scale aerosol transport models, J. Geophys. Res., 109, D22202, doi:10.1029/2003JD004485, 2004.

Winkler, P. M., Vrtala, A., Rudolf, R., Wagner, P.E., Riipinen, I., Vesala, T., Lehtinen, K. E. J., Viisanen, Y., and Kulmala, M.: Condensation of water vapor: Experimental determination of mass and thermal accommodation coefficients, J. Geophys. Res., 111, D19202, doi:10.1029/2006JD007194, 2006. 